\title{
Measuring the Current Patient Safety Culture in Public General Hospitals of Southern Nations Nationalities and Peoples Region (SNNPR), Ethiopia: Perspective of Health Care Workers
}

\author{
Ejajo $T^{1}$, Arega $A^{2 *}$ and Batebo $B^{3}$ \\ ${ }^{1}$ Department of Public Health, Dilla University, Ethiopia \\ ${ }^{2}$ Department of Health Education and Behavioral \\ Sciences, J imma University, Jimma, Ethiopia \\ ${ }^{3}$ Hadiya Zone Health Department, Southern Nations, \\ Nationalities and Peoples, Ethiopia \\ *Corresponding author: Abinet Arega, Department \\ of Health Education and Behavioral Sciences, Jimma \\ University, J imma, Ethiopia
}

Received: July 27, 2017; Accepted: August 21, 2017; Published: August 28, 2017

\begin{abstract}
Background: Patient safety is crucial to the quality of patient care and remains challenging for countries at all levels of development. There is a popular acknowledgement of the importance of establishing patient safety culture in healthcare organizations. As a result, assessing patient safety culture and frequent event reporting in healthcare organizations has become a common activity to improve quality of health care.
\end{abstract}

Objective: The aim of this study was to examine the current patient safety culture from the perspective of healthcare workers in Southern Nations Nationalities and Peoples Region Public General Hospitals.

Methods: A cross-sectional study conducted fromFebruary 16 to March 16, 2015 using Hospital Survey on Patient Safety Culture questionnaire, which has 12 dimensions. Overall, we distributed 540 questionnaires and received 433 respondents. Patient safety grade and number of event reports computed descriptively. Then, the effect of various independent variables on frequency of events reported had assessed using multiple linear regressions analysis. Data were analyzed using SPSS version 16.0. In all cases, $\mathrm{P}<0.05$ and $95 \%$ confidence interval had used to check statistical associations.

Results: The overall patient safety grade as rated by the participants was acceptable (58.4\%) and poor (20.1\%). PSC (patient safety culture) dimensions found to have a significant association with frequency of events reported in the studied hospitals. Overall perceptions of safety and Non-punitive response to error were positively associated with frequency of events reported $(\beta=1.052$, $0.44, \mathrm{P}=0.000$ ). Organizational learning and continuous improvement, Communication openness and feedback about error, Teamwork across and within hospital unit were also positively associated with frequency of events reported at $(\mathrm{P}<0.001)$.

Conclusion: This study indicated that poor PSC dimension system and low event reporting frequency in the respective hospitals, and there should be strong work on PSC dimension to increase frequency of event reporting.

Keywords: Patient safety culture; Frequency of events reported; An event

\section{Background}

Patient safety is the central theme and ultimate objective of health care quality. The World Health Organization (WHO) has defined patient safety as "the reduction of risk of unnecessary harm associated with healthcare to an acceptable minimum" [1].

Health care organizations around the world have lately observed to pay more attention to the importance of establishing a culture of safety. To achieve a culture of safety, it is necessary to understand the principles, attitudes, and standards related to an organization and what behavior related to patient safety are expected and appropriate [2].

According to WHO estimates tens of millions of patients worldwide endure disabling injuries or death each year that relate directly to unsafe medical practices and care. "It also affects the lives of doctors, nurses and other health care staff who become the 'second victims' in a chain of events. "The incidence of medical errors during healthcare procedures is $7.5 \%$, and majorities of the adverse events has identified as preventable [3]. For instance, a Harvard Medical Study of an acute care hospital in 1984 found an adverse event rate of $3.8 \%$. Similarly, in 1992, a study on quality in Australian acute care hospitals found the rate to be $16.6 \%$. Furthermore, studies conducted in acute care hospitals in UK (1999-2000), Denmark (1998), New Zealand (1998) and Canada (2001) found the adverse event rates to be $11.7 \%, 9.0 \%, 12.9 \%$, and $7.5 \%$ respectively [4].

It is likely that millions of patients globally suffer from injuries,
J Fam Med - Volume 4 Issue 5 - 2017

ISSN : 2380-0658 | www.austinpublishing group.com

Ejajo et al. (C) All rights are reserved
Citation: Ejajo T, Arega A and Batebo B. Measuring the Current Patient Safety Culture in Public General Hospitals of Southern Nations Nationalities and Peoples Region (SNNPR), Ethiopia: Perspective of Health Care Workers. J Fam Med. 2017; 4(5): 1124 
disabilities or even death due to medical errors. WHO reported an adverse event rate of about 10 percent [1], which would mean that one in every ten patients facing suffers from adverse events. Twenty five percent of patients in ambulatory care practices experience adverse drug events [5]. Commonwealth Fund studies in 2002 revealed that 25 percent of patients across four countries reported that they had experienced some form of medical error in the past two years [6]. Although medical errors happen in countries at all levels of development, there is a fear that developing countries may affected disproportionately.

In developed countries, information technologies are increasingly been used in healthcare to improve patient safety. Studies have shown that Computerized Physician Order Entry (CPOE), especially when combined with Decision Support System (DSS), improves patient safety [7].

"In the African Region, most countries lack national policies on safe health-care practices. Inappropriate funding and unavailability of critical support systems including strategies, guidelines, tools and patient safety standards remain major concerns in the region." Furthermore, the report implied that understanding of the problems associated with patient safety has hampered by inadequate data [8].

Circumstantial evidences show that almost all medical errors have been treated traditionally through blaming, shaming and punishment. Moreover, most medical errors have not reported and/ or hidden. Consequently; health professionals and managers are not in a position to learn from mistakes committed in the health care institutions" [9]. Therefore, this study concerning to measure the current patient safety culture in public general hospitals of the southern nations nationalities and peoples region.

\section{Methods}

\section{Study setting and design}

A cross-sectional institution based study design was conducted from February 16 to March 16, 2015 among randomly selected health professionals in three selected general hospitals of SNNPR. The region is located in the Southern and south-western part of Ethiopia. Its capital city Hawassa is located $275 \mathrm{~km}$ far away from Addis Ababa. The region has 15 zones, 4 special woredas, 156 woredas, 22-reform town, 3602 rural kebeles, and 324 urban kebele.

\section{Study populations}

The study population comprised of sampled health professionals from all units of the hospital who were full-time employees in three selected general hospitals of SNNPR.

\section{Sample size and sampling procedures}

$50 \%$ of the general hospitals in the region have selected randomly by lottery method; Butajiara from Gurage, Queen Eleni Mohammed from Hadiya, and Yirgalem general hospital from Sidama zone were included.

The list of health workers compiled from the management of each participating hospital. This helped us to track the distribution and collection of the questionnaire.

To have sufficient number of participants from each of the general hospitals, average number of staff was looked at each hospital. "All health workers fulfilling the inclusion criteria were included in the study" [9]. A total 540 questionnaires distributed to hospitals.

\section{Data collection}

The AHRQ Hospital Survey tool for patient safety culture, which was already used in various countries (United States, Saudi Arabia, Canada, the United Kingdom, Belgium, Denmark, Norway, Ethiopia and Taiwan), was used to ask hospital staff about patient safety issue, medical error and event reporting (9, Error! Reference source not found., Error! Reference source not found., Error! Reference source not found., 11, Error! Reference source not found., Error! Reference source not found., 16). For this study, the questionnaire translated into the Amharic language using forward translation technique. Fivepoint Likert scale of agreement (strongly disagree, disagree, neutral, agree and strongly agree) or frequency (never, rarely, sometimes, most of the time, always) were used to ask respondents to rate each item of patient safety dimensions. The instrument includes eight items that ask respondents to provide limited background information related to their work.

\section{Study variables}

The dependent variable was patient safety culture as measured by frequency of events reported. Independent variables:- teamwork across and within hospital units, Management expectation and support to patient safety, hospital handoffs \& transitions, organizational learning and continuous improvement, communication openness and feedback about errors, non-punitive responses to error, overall perceptions of patient safety, and respondents characteristics and work experiences.

\section{Statistical analysis}

The Hospital Survey on Patient Safety Culture (HSOPSC) is composed of 42 items that measure 12 composites. The HSOPSC included both positively and negatively worded items. Items had scored on a five-point frequency scale (including a neutral category).

Descriptive statistics for the characteristics of respondents and survey items had analyzed. It used to present frequency information about the characteristics of all the respondents as a whole, for example, the units to which they belong, how long they have worked in the hospital or their unit, their staff position, etc. Negatively worded items reversed to ensure that positive answers indicated a higher score.

To obtain the dimensions scores, item percent positive scores computed first and then the scores had averaged, which gives weight to each item in a composite.

The HSOPSC also included questions on the number of events reported over the past 12 months and the patient safety grade that respondents gave to their work area/unit and they had described by their frequency.

Reliability test was performed using the patient safety dimensions involved in measuring patient safety as frequency of events reported and Cronbachs alpha was calculated to be greater than 0.7. The variables, which employed to compute the alpha value, entered in to the principal component analysis. Factors having Eigenvalue greater than one after the scale was treated. At the end of the principal component analysis, the dimensions obtained as a continuous scale. 
Table 1: Descriptions of patient safety measure dimensions after item reduction using PCA at SNNPR Public general hospitals February 16 to March $16,2015$.

\begin{tabular}{|c|c|c|c|c|}
\hline Patient safety measure dimensions & $\begin{array}{l}\text { Number } \\
\text { of items }\end{array}$ & $\begin{array}{l}\text { Cronbach"s } \\
\text { alpha }\end{array}$ & $\mathrm{KMO}$ & variance \\
\hline Management expectation and support to patient safety & 7 & 0.75 & 0.5 & 60.5 \\
\hline Organizational learning and continuous improvement & 3 & 0.76 & 0.5 & 64.5 \\
\hline Teamwork across and within hospital unit & 8 & 0.83 & 0.58 & 63 \\
\hline Communication openness and Feedback and communication about error & 3 & 0.78 & 0.68 & 82.3 \\
\hline Non-punitive response to error & 3 & 0.79 & 0.56 & 74 \\
\hline Hospital handoffs and transition & 4 & 0.8 & 0.5 & 87 \\
\hline Overall perceptions of safety & 4 & 0.74 & 0.5 & 60 \\
\hline Staffing & 3 & 0.43 & & \\
\hline
\end{tabular}

All originally defined items used, except staffing due to cronbachs alpha below 0.7. Internal consistency became more acceptable with the factors, "communication openness and feedback and communication about error" combined into one six-item factor, "teamwork across hospital units and teamwork within units" combined into one eight-item factor, "supervisor/manager expectations and actions promoting patient safety and hospital management support for safety", combined into one seven-item factor, supporting 7-factor model. All the components/factors had summarized (Table 1).

One-way ANOVA Analysis assessed the mean differences in each of the positive responsescores among the three hospitals in our study.

Three different models to assess the effect of various variables on frequency of events reported conducted linear regression analysis. In the first model, the effects of respondents characteristics, work experience and access to patient has assessed. In the second model, effects of different dimensions of PSC factors had assessed to test their association with patient safety culture as measured by frequency of events reported. In the previous two models those had significant association were included in the final model.

The data entered into Epi Data version 3.1 to edit and clean for inconsistencies and missing values and analyzed using SPSS 16.0. In all cases, $\mathrm{P}<0.05$ and $95 \%$ confidence interval used to check statistical significance.

\section{Ethical considerations}

Institutional Review Board of college of Health sciences of Jimma University approved the proposal before the conduct of the study. Letter of permission obtained from the SNNPR Health Bureau and from the respective hospitals. All the study participants informed about the purpose of the study and finally their verbal consent obtained prior to giving them self-administered questionnaire. The respondents assured their right to refuse or terminate at any point of the interview. The information provided by each respondent kept confidential.

\section{Results}

\section{Socioeconomic and demographic characteristics}

The Hospital Survey on Patient Safety Culture questionnaires distributed to 540 health workers and 433 respondents completed the survey (response rate of 80\%). From the respondents 165 (38.1\%) are working in Queen Eleni Mohamed Memorial Hospital (QEMH). More than half of the respondents were male $53.8 \%$ (233), and the age of the respondents falls between 30 to 40 years. They were mainly nurses, $54.7 \%$ (237) and followed by medical doctors (74) $17.1 \%$ (Table 2).

\section{Patient safety grade and number of events reported}

The percentage of respondents who gave an excellent or very good grade to their hospitals was $2.1 \%$ and $16.9 \%$. The majority, $58.4 \%$, in the studied hospitals felt that the situation is just acceptable or medium, while $20.1 \%$ and $2.5 \%$ gave a poor and failing grade respectively. Substantial numbers of an event never or rarely reported over the last 12 months. The results apparently show that $34.4 \%$ of respondents had not reported a single event and just $62.8 \%$ had reported 1 or 2 events.

\section{Frequency of the positive respondents towards patient safety dimension}

Positive responses to PSC components have ranged from 6.5\% to $79.7 \%$. Areas of strength in our hospitals were teamwork across and within hospital unit (79.7\%). Others with PSC components below $75 \%$ are areas with potential for improvement (25). The lowest positive responses identified by the respondents were hospital handoffs and transition (6.5\%). No respondents answered neutral scale in our study.

\section{Comparison of positive response of the PSC dimension scores among the three hospitals}

One-way ANOVA Analysis conducted to assess the mean difference of positive percentage responses for each of dimension scores of PSC across the hospitals in our study. Significant differences had found among the three hospitals in four dimensions. "Teamwork across and within hospital unit” was 75\% for QEMH, 72.3\% for Yirgalem hospital, and 91\% for Butajira hospital at a significant level of $\mathrm{p}=0.046$. "Organizational learning and continuous improvement" was $49.55 \%$ for QEMH, $47.7 \%$ for Yirgalem hospital, and $72.1 \%$ for Butajira hospital at a significant level of $\mathrm{P}=0.001$. "Management expectation and support to patient safety" was 59\% for QEMH, $67 \%$ for Yirgalem hospitals, and $80.45 \%$ for Butajira hospital at a significant level of $\mathrm{P}=0.023$. "Communication openness and feedback about error" was 63\% for QEMH, 59.5\% for Yirgalem hospital, and $89.4 \%$ for Butajira hospital at a significant level of $\mathrm{P}=0.0025$.

However, Overall perceptions of safety, Hospital handoffs and transition, and Non-punitive response to error were no significant differences of dimensions score among the three general hospitals (Table 3). 
Table 2: Characteristics of the study respondents at SNNPR Public general hospitals February 16 to March 16, $2015(n=433)$.

\begin{tabular}{|c|c|c|c|}
\hline Variables & Category & $\begin{array}{l}\text { Frequency } \\
\text { (N) }\end{array}$ & $(\%)$ \\
\hline \multirow{3}{*}{ Hospitals } & $\begin{array}{c}\text { Queen Eleni } \\
\text { Mohamed }\end{array}$ & 165 & 38.1 \\
\hline & Yirgalem & 128 & 29.6 \\
\hline & Butajira & 140 & 32.3 \\
\hline \multirow{2}{*}{ Sex } & Male & 233 & 53.8 \\
\hline & Female & 200 & 46.2 \\
\hline \multirow{3}{*}{ Age } & $<30$ & 196 & 45.3 \\
\hline & $30-40$ & 225 & 52 \\
\hline & $41-50$ & 12 & 2.8 \\
\hline \multirow{3}{*}{$\begin{array}{c}\text { Highest level of education } \\
\text { achieved }\end{array}$} & Diploma & 216 & 49.9 \\
\hline & Bachelor degree & 196 & 45.3 \\
\hline & Masters and above & 21 & 4.8 \\
\hline \multirow{5}{*}{ Staff position/profession } & medical doctor & 74 & 17.1 \\
\hline & Nurse & 237 & 54.7 \\
\hline & $\begin{array}{l}\text { technician/lab, } \\
\text { radiology }\end{array}$ & 46 & 10.6 \\
\hline & pharmacy & 59 & 13.6 \\
\hline & other specify* & 17 & 3.9 \\
\hline \multirow{4}{*}{$\begin{array}{l}\text { Duration of experience in this } \\
\text { hospital }\end{array}$} & $<1$ year & 5 & 1.1 \\
\hline & 1-5 year & 335 & 77.4 \\
\hline & 6-10 year & 86 & 19.9 \\
\hline & 11-15 year & 7 & 1.6 \\
\hline \multirow{3}{*}{$\begin{array}{l}\text { Duration of experience in work } \\
\text { area/unit }\end{array}$} & $<1$ year & 175 & 40.4 \\
\hline & 1-5 year & 243 & 56.1 \\
\hline & $6-10$ year & 15 & 3.5 \\
\hline \multirow{4}{*}{ Number of hours per week } & 20-30 hours & 14 & 3.2 \\
\hline & 40-59 hours & 273 & 63.1 \\
\hline & $60-79$ hours & 127 & 29.3 \\
\hline & 80-99 hours & 19 & 4.4 \\
\hline \multirow{9}{*}{ Primary work area or unit } & many different units & 26 & 6 \\
\hline & emergency & 38 & 8.8 \\
\hline & medical non-surgical & 66 & 15.2 \\
\hline & surgical & 113 & 26.1 \\
\hline & obstetrics & 48 & 11.1 \\
\hline & pediatrician & 24 & 5.5 \\
\hline & pharmacy & 59 & 13.6 \\
\hline & laboratory & 29 & 6.7 \\
\hline & other specify** & 30 & 7 \\
\hline
\end{tabular}

(Reference others ${ }^{*}=$ anesthesia, health officer, midwifes; other ${ }^{* *}=$ radiology, physiotherapy)

\section{Respondent character as predictors of patient safety}

The impact of respondents characteristics on patient safety culture as measured by frequency of events reported sores in the first model assessed (Table 4). In this model respondents character predictor variables such as sex, age, duration of experience in hospital unit, duration of experience in work unit, staff position and primary work area or unit explained $41 \%$ of the variance in the frequency
Table 3: Comparison of positive response of the PSC dimension scores among the three hospitals at SNNPR Public general hospitals February 16 to March 16, 2015.

\begin{tabular}{|c|c|c|c|c|}
\hline \multirow{2}{*}{ Dimensions of patient safety } & \multicolumn{3}{|c|}{$\begin{array}{l}\text { Hospitals positive response } \\
\text { score }\end{array}$} & \multirow[t]{2}{*}{ P-value } \\
\hline & QEMH & Yirgalem & Butajira & \\
\hline Overall perceptions of safety & $19 \%$ & $30 \%$ & $33.60 \%$ & 0.56 \\
\hline Hospital handoffs and transition & $2.70 \%$ & $12.60 \%$ & $4.50 \%$ & 0.78 \\
\hline Non-punitive response to error & $52 \%$ & $46 \%$ & $65.50 \%$ & 0,67 \\
\hline $\begin{array}{l}\text { Organizational learning and continuous } \\
\text { improvement }\end{array}$ & $49.50 \%$ & $47.70 \%$ & $72.10 \%$ & 0.001 \\
\hline $\begin{array}{l}\text { Management expectation and support } \\
\text { to patient safety }\end{array}$ & $59 \%$ & $67 \%$ & $80.40 \%$ & 0.023 \\
\hline $\begin{array}{c}\text { Communication openness and } \\
\text { feedback about error }\end{array}$ & $63 \%$ & $59.50 \%$ & $89.40 \%$ & 0.0025 \\
\hline $\begin{array}{c}\text { Teamwork across and within hospital } \\
\text { unit }\end{array}$ & $75 \%$ & $72.30 \%$ & $91 \%$ & 0.046 \\
\hline
\end{tabular}

of events reported given by the participants $\left(\mathrm{R}^{2}=0.411\right.$, ). Females respondents had directly related with the score of frequency of event report $(\beta=0.194, p=0.044)$. Respondents whose age ranged below 30 years had associated with the frequency of events reported score $(\beta=-$ $0.201, \mathrm{P}=0.04)$. Duration of experience in work hospital ranged from 6 to 10 years was directly related with the score of frequency of events reported ( $\beta=0.369, P=0.002$ ). Moreover, significant association were observed for pharmacy taken together frequency of events reported score $(\beta=0.756, \mathrm{P}=0.000)$. Working at Butajira hospitals had direct relation with frequency of events reported score $(\beta=1.13, \mathrm{p}=000)$ and working at Yirgalem hospital had association with scores of the frequency of events reported $(\beta=0.815, \mathrm{P}=000)$. Here all the variables that had $\mathrm{p}$.

\section{Dimensions of patient safety as predictors of frequency of events reported}

In the second model, PSC factor scores were included and tested the association on patient safety culture as measured by frequency of events reported. After the reduction of composite variable by using principal component analysis, one composite variable identified from each safety culture dimensions. In this part the effect of each independent variables/safety culture dimensions (Overall perceptions of safety, Hospital handoffs and transitions, Nonpunitive response to error, Organizational learning and continuous improvement, Management expectation and support to patient safety, Communication openness and feedback about error and Teamwork across and within hospital unit) were tested for association on frequency of events reported (Table 5).

\section{Linear multiple regression for patient safety composite component scores and respondents characteristics}

In this model variable included, explain $69 \%$ of the variance in the frequency of events reported score $(\mathrm{R}$ square $=0.69)$. Respondents working at Butajira hospitals had 0.63 unit greater frequency of events reported score $(\beta=0.63, p=034)$ and those working at Yirgalem had 0.47 unit greater scores in the frequency of events reported ( $\beta$ $=0.47, \mathrm{P}=028)$ when compared to those from the QEMH respectively. Females respondents had 0.14 higher score frequency of event reported than male $(\beta=0.14, p=0.031)$. Duration of experience in work hospital ranged from 6 to 10 years was directly related with the score of frequency of events reported $(\beta=0.302, \mathrm{P}=0.02)$. This implies that respondents whose experience in work hospital ranged from 6 to 
Table 4: Respondent character as Predictors of Patient Safety at SNNPR Public general hospitals February 16 to March 16, 2015 ( $n=433$ ).

\begin{tabular}{|c|c|c|c|c|c|c|}
\hline \multirow{2}{*}{\multicolumn{2}{|c|}{ Respondents characteristics }} & \multirow{2}{*}{\multicolumn{2}{|c|}{$\begin{array}{l}\text { Unstandardized } \\
\text { Coefficients }\end{array}$}} & \multirow{2}{*}{$\begin{array}{l}p \\
0\end{array}$} & \multirow{2}{*}{\multicolumn{2}{|c|}{ 95\% Confidence Interval for $\beta$}} \\
\hline & & & & & & \\
\hline \multirow[b]{2}{*}{ Hospitals } & QEMH* $^{*}$ & & & & & \\
\hline & Yirgalem & 0.815 & 0.103 & 0 & 0.613 & 1.017 \\
\hline \multirow{2}{*}{ Sex } & Male* & & & & & \\
\hline & Female & 0.194 & 0.0961 & $0.04419 * \star$ & 0.01 & 0.38 \\
\hline \multirow{3}{*}{ Age } & $<30$ & -0.201 & 0.097 & $0.04^{\star \star *}$ & -0.393 & -0.009 \\
\hline & $30-40^{*}$ & & & & & \\
\hline & $41-50$ & -0.062 & 0.295 & 0.834 & 0.643 & 0.519 \\
\hline \multirow[t]{2}{*}{ Highest level of education achieved } & Bachelor degree & 0.032 & 0.099 & 0.746 & -0.162 & 0.226 \\
\hline & $\begin{array}{l}\text { Masters } \\
\text { And above }\end{array}$ & -0.199 & 0.229 & 0.384 & -0.649 & 0.251 \\
\hline \multirow{4}{*}{ Duration of experience in work hospital } & $<1$ year & 0.949 & 0.445 & $0.034^{\star *}$ & 0.074 & 1.823 \\
\hline & $1-5$ year* $^{*}$ & & & & & \\
\hline & 6-10 year & 0.369 & 0.119 & $0.002^{\star \star}$ & 0.134 & 0.603 \\
\hline & $11-15$ year & -0.258 & 0.377 & 0.494 & -0.999 & 0.483 \\
\hline \multirow{3}{*}{ Duration of experience in work area/unit } & $<1$ year & -0.068 & 0.098 & 0.492 & -0.261 & 0.126 \\
\hline & $1-5$ year* $^{*}$ & & & & & \\
\hline & 6-10 year & -0.823 & 0.264 & $0.002^{* \star *}$ & -1.341 & -0.305 \\
\hline \multirow{3}{*}{ Number of hours per week } & 20-30 hours & -0.033 & 0.172 & 0.846 & -0.371 & 0.304 \\
\hline & 40-59 hours* & & & & & \\
\hline & 80-99 hours & -0.241 & 0.193 & 0.211 & -0.62 & 0.137 \\
\hline \multirow{5}{*}{ Staff position } & Medical doctor & 0.153 & 0.128 & 0.233 & -0.099 & 0.406 \\
\hline & Nurse* & & & & & \\
\hline & Laboratory & 0.005 & 0.155 & 0.972 & -0.3 & 0.311 \\
\hline & Pharmacy & 0.756 & 0.14 & $0.000^{\star *}$ & 0.48 & 1.031 \\
\hline & Other specify & 0.768 & 0.242 & $0.002^{\star *}$ & 0.293 & 1.244 \\
\hline \multirow{7}{*}{ Primary work area or unit } & Many different units & -0.146 & 0.2 & 0.467 & -0.539 & 0.247 \\
\hline & Emergency & -0.402 & 0.17 & $0.018^{\star \star \star}$ & -0.736 & -0.069 \\
\hline & Surgical* & & & & & \\
\hline & Obstetrics & 0.291 & 0.154 & 0.06 & -0.012 & 0.593 \\
\hline & Pediatrician & 0.282 & 0.207 & 0.174 & -0.125 & 0.69 \\
\hline & Pharmacy & 0.68 & 0.142 & $0.000^{* *}$ & 0.401 & 0.959 \\
\hline & Laboratory & -0.185 & 0.191 & 0.333 & -0.559 & 0.19 \\
\hline
\end{tabular}

$\mathrm{R}=0.46, \mathrm{R}$ square $=0.41$, Adjusted $\mathrm{R}$ square $=0.34$.

$\left({ }^{*}=\right.$ reference,${ }^{* *}=$ direct relation, ${ }^{* *}=$ inverse relation $)$.

10 years had 0.302 higher score for event reported than respondents experiences ranged from 1 to 5 years (Table 6).

\section{Discussion}

The incidence of medical errors during healthcare procedures is $7.5 \%$, and majorities of the adverse events has identified as preventable [3]. For instance, a Harvard Medical Study of an acute care hospital in 1984 found an adverse event rate of 3.8\%. Similarly, in 1992, a study on quality in Australian acute care hospitals found the rate to be $16.6 \%$. Furthermore, studies conducted in acute care hospitals in UK (1999-2000), Denmark (1998), New Zealand (1998) and Canada (2001) found the adverse event rates to be $11.7 \%, 9.0 \%$, $12.9 \%$, and $7.5 \%$ respectively [4]. Our study indicated that health workers in the respective hospitals rated their hospital as acceptable/ 
Table 5: Dimension of Patient Safety as Predictors of Frequency of events reported score at SNNPR Public general hospitals February 16 to March $16,2015$.

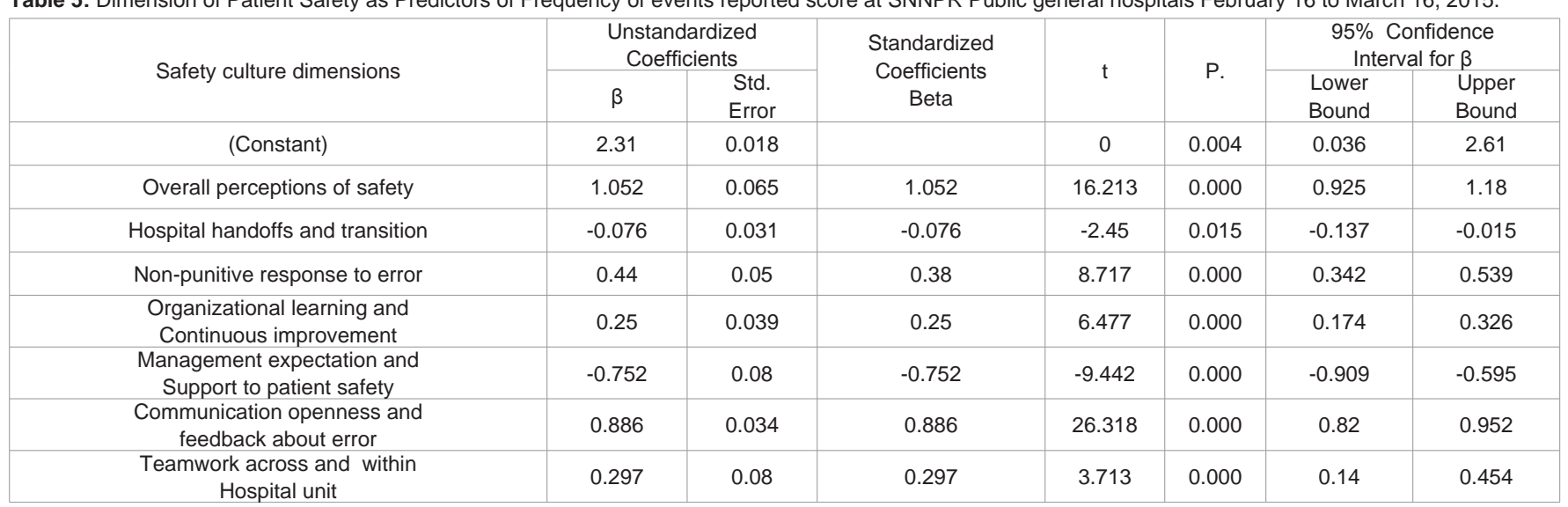

Table 6: Multiple regression results showing the relationship between all variables and frequency of events reported score at SNNPR Public general hospitals, February 16 to March 16, 2015

\begin{tabular}{|c|c|c|c|c|c|c|}
\hline \multirow{3}{*}{ Variables } & \multirow{3}{*}{ Category } & \multicolumn{2}{|c|}{$\begin{array}{l}\text { Unstandardized } \\
\text { Coefficients }\end{array}$} & \multirow{3}{*}{$\mathrm{p}$} & \multirow{2}{*}{\multicolumn{2}{|c|}{$\begin{array}{c}95 \% \\
\text { Confidence } \\
\text { Interval for } \beta\end{array}$}} \\
\hline & & \multirow[b]{2}{*}{$\beta$} & \multirow{2}{*}{$\begin{array}{l}\text { Std. } \\
\text { Error }\end{array}$} & & & \\
\hline & & & & & $\begin{array}{l}\text { Lower } \\
\text { Bound }\end{array}$ & $\begin{array}{l}\text { Upper } \\
\text { Bound }\end{array}$ \\
\hline (Constant) & & 0.84 & 0.143 & 0 & 0.558 & 1.122 \\
\hline \multirow{3}{*}{ Hospitals } & QEMH* $^{*}$ & & & & & \\
\hline & Yirgalem & 0.47 & 0.043 & 0.028 & 0.27 & 0.917 \\
\hline & Butajira & 0.63 & 0.03 & 0.034 & 0.451 & 1.12 \\
\hline \multirow{2}{*}{ Sex } & Male* $^{\star}$ & & & & & \\
\hline & Female & 0.14 & 0.0361 & $0.031^{* *}$ & 0.012 & 0.37 \\
\hline \multirow{2}{*}{$\begin{array}{l}\text { Duration of experience } \\
\text { in work hospital }\end{array}$} & $1-5$ year* & & & & & \\
\hline & $6-10$ year & 0.302 & 0.017 & $0.02^{\star *}$ & 0.114 & 0.523 \\
\hline \multirow{2}{*}{ Staff position } & Nurse* & & & & & \\
\hline & Pharmacy & 0.564 & 0.013 & $0.01 * *$ & 0.34 & 0.902 \\
\hline \multirow{3}{*}{ Primary work area or unit } & Many different units & -0.312 & 0.065 & $0.031^{\star * *}$ & -0.583 & -0.204 \\
\hline & Emergency & -0.384 & 0.025 & $0.001^{\star \star *}$ & -0.407 & -0.108 \\
\hline & Surgical* & & & & & \\
\hline \multirow{6}{*}{ Components/composite } & Overall perceptions of safety & 0.92 & 0.018 & 0.01 & 0.995 & 1.32 \\
\hline & $\begin{array}{c}\text { Organizational learning } \\
\text { And continuous improvement }\end{array}$ & 0.75 & 0.066 & 0.002 & 0.61 & 0.934 \\
\hline & Non-punitive response to error & 0.11 & 0.01 & 0.012 & 0.024 & 0.413 \\
\hline & $\begin{array}{c}\text { Management expectation and support } \\
\text { to patient safety }\end{array}$ & -0.502 & 0.05 & 0.038 & -0.814 & -0.378 \\
\hline & $\begin{array}{c}\text { Communication openness and feedback } \\
\text { about error }\end{array}$ & 0.607 & 0.024 & 0.012 & 0.71 & 0.911 \\
\hline & Teamwork across and within hospital unit & 0.12 & 0.06 & 0.027 & 0.03 & 0.304 \\
\hline
\end{tabular}

medium grade (58.4\%) and event reported rate no event reported (34.4\%) and 1 to 2 event reported (62.8\%) in 12 months. There is similarity with above findings, as our study result the patient safety culture is in risk, because this trend may leads to high adverse events and medical errors.

In this study with regard to the grading of hospitals patient safety culture, very few of the respondents, either grades their hospitals excellent or very good, $2.1 \%$ and $16.9 \%$ respectively. It is much fewer when compared with benchmark data of AHRQ 2012, 30\% and 45\% respectively [10]. On the other hand, with respect to the number of events reported over the past 12 months, more than half of the respondents indicated 1 to 2 events reported. Indicated in the similar study; Health care workers are less likely to grade excellent/very good and report events, especially physicians and nurses more likely grade poor/failing and no events reported $[11,12]$. This had attributed to many reasons including blame, shame and lack of proper reporting system in place. Encouraging health professionals, specifically nurses, to report events in a non-punitive environment is crucial for improving patient safety. Frequency of events reported had found to increase with increasing how often staff reports all types of mistakes, such as latent errors, accidents, and near misses. Reporting errors improves the quality of care for future patients $[11,13]$. In our study, 
the analysis of results identified those patient safety culture predictors such as sex, duration of experience, staff position and primary work area in accordance with characteristics of respondents were associated with the patient safety culture as measured by frequency of events reported.

The overall perceptions to safety score for this study was $27.3 \%$, lower than the AHRQ (2012) score of 63\% (10). This result indicates that healthcare workers are not highly positive about patient safety culture in SNNPR public general hospitals. There is also the same study in Taiwan had 53\% score, it is higher than our finding and indicates there is room for improvement in our hospitals [14].

In the SNNPR, we found that the majority of dimensional-level scores were lower than the AHRQ (2012) benchmark report. The dimensions „Teamwork across and within hospital unit received the highest positive response rate. Similar results had found in studies conducted in Taiwan [15]. Teamwork is an essential part of the development of patient safety culture, and staff should be encouraged and supported in their efforts to establish good relationships with people working in the same unit and other units [3]. We believe that teamwork in the SNNPR public general hospitals is a strength that has used to create an enabling environment to develop a patient safety culture.

In our study variables included in the final model explain $69 \%$ of the variance in the frequency of events reported score ( $\mathrm{R}$ square $=$ 0.69). The finding implies that system/PSC dimension factors are the most important factors in patient safety culture and causes of medical errors in the hospital and poor frequency of events reported. Overall perceptions of safety, Non-punitive response to error, Organizational learning and continuous improvement, Management expectation and support to patient safety, Communication openness and feedback about error and Teamwork across and within hospital unit explained frequency of events reported.

Likewise, as experiential evidences have revealed the root causes of medical errors are primarily the system factors include poor communication, unclear lines of authority between care providers, disconnected reporting systems within hospitals, and inadequate reporting frequency systems of events to share information about errors [16].

In our finding system/PSC dimension related factors such as management expectation and support to patient safety, overall perceptions to safety, non-punitive response to error, organizational learning and continuous improvement, communication openness and feedback about error and teamwork across and within units were associated with the patient safety culture as measured by frequency of events reported. In the same study communication openness and feedback about errors, teamwork across hospital units and non-punitive response to error was significantly associated with frequency of event reporting at $(p<0.05)$ [17]. Teamwork within and across hospital units is critical in a healthcare environment as the patient is usually treated by several healthcare practitioners and specialists in multiple settings [11]. In the other study our finding was strengthen that teamwork across and within hospital unit were directly influencing patient safety outcome $(\mathrm{p}<0.05)$ [9].

Proper communication within and across healthcare teams is essential to remove any threats to safety of patients and essential to increase frequency of events reported. Communication problems have identified as major contributing factors to adverse events [18]. An analysis of 2,455 sentinel events reported to the Joint Commission on the Accreditation of Healthcare Organizations showed that 70\% of the cases were a result of failure in communication [18]. We found that communication openness was directly associated with frequency of events reported.

In order for a patient safety program to be, successful, strong leadership needed. When leadership and management is committed to a culture of safety, the whole organization will follow and thus disclosing an events and finding their root causes will become an organizational process [19].

This finding also answered the final objectives of this study "To identify the factors related to patient safety culture in SNNPR public general hospitals." Using regression analysis most of the dimensions was significant $(\mathrm{P}<0.001)$, which means each dimensions has an influence on the patient safety culture [15]. However, using multiple regression analysis, found all dimensions to be associated with patient safety culture as measured by frequency of events reported except hospital handoffs and transition. The slight variation in our results compared other finding could be due to the differences in the study settings and time.

\section{Limitations of the Study}

This study was limited to only public general hospitals in SNNPR; therefore, the result cannot apply to other categories of health care organizations.

In addition, the sample included only health workers. That perception of other administrative body was not included.

\section{Conclusions and Recommendations}

The majority of the respondents considers to the present patient safety culture in our hospitals just acceptable/medium and more than half of the respondents indicated that 1 to 2 events reported in the past 12 months. The realization of an acceptable environment of patient safety depends on the changing the perceptions of the healthcare workers towards positive patient safety culture. As indicated in the result section PSC is poor and need special attentions.

The strong relationships between independent and dependent variable (patient safety culture) as measured by frequency of events reported in this study also revealed in the result of multiple linear regression analysis. These result indicated that most of the independent variables have influence on the patient safety culture in the SNNPR public general hospitals.

However, our result shown that all factors (patient safety dimensions) except hospital handoffs and transition pertaining to patient safety culture had found to significant relationship with patient safety culture as measure by frequency of events reported in respective studied hospitals. There as a result great effort has needed to improve frequency of event reporting.

\section{Recommendations}

There is a need for concrete interventions to implement the 
concept of patient safety culture. The strengthening and further integration of the patient safety concept especially event reporting into the continuous professional training curriculum for health care professionals is highly recommended. In order to achieve that, patient safety should have prioritized on the agenda of the SNNPR health bureau and all stakeholders to improve patient safety in the region.

They should establish and strong follow up patient safety committee to assess every aspect of activities related to patient safety culture in the SNNPR general hospitals.

On the contrary, health care workers should be encouraged to report errors for the purpose of learning and improvement. This would require formulation of policies that promote the establishment of non-punitive environments. There is need for broadly based research in to patient safety culture, which should include all categories of health care organizations in the region. That our study was only focused general hospitals.

Our study finding suggested that an effective event reporting frequency should initiated, supported, and maintained in the SNNPR general hospitals. Generally, patient safety can best achieved by paying close attention to patient safety culture. Health care organizations should implement patient safety culture and give strong support for safety activities to improve patient safety.

Therefore, in an effort to implement patient safety culture all these patient safety system related factors should be considered, without disregarding any single dimension especially those with strong associations/significant differences with frequency of events reported.

Finally, SNNPR public general hospitals should focus on each of these dimensions in order to improve frequency of events reported that improve patient safety culture.

\section{Acknowledgments}

The authors would like to thank the respondents participated in the study. They are also grateful to Jimma University for funding the study.

\section{Author Contributions}

TE conceived, designed the study, participated in the data collection, analyzed the data, interpretation of data, and drafted the manuscript. BB and AA participated in designing the study, data analysis, interpretation of data, revised, and edited the manuscript. All authors read and approved the final version of the manuscript.

\section{References}

1. World Health Organization (WHO). Conceptual framework for the international classification of patient safety Version 1.1; Final technical report, January 2009.
2. World Health Organization (WHO). Communication during Patient Handovers; Patient Solutions Volume 1, Solution 3; May 2007.

3. Bondur S and Fizi E. A survey on patient safety culture in primary healthcare services: Turkey; 2009; 21: 348-355

4. WHO Library Cataloguing-in-publication Data, World Alliance for Patient Safety Forward program ISBN, 2004.

5. Gandhi TK, Weingart SN, Borus J, Segar AC, Peterson S, Burdick E, et al. Adverse drugs event in ambulatory care. New England Journal of Medicine. 2003; 348: 1556-1564.

6. Blendon RJ, Schoen C, DesRoches C, Osborn R, Zaper K. Common concerns amid Diverse System: Health Affairs. 2003; 22: 106-121.

7. Ball MJ \& Douglas JV. Redefining and Improving Patient Safety Health Link. Methods Inf Med. 2002; 41: 271-276.

8. Regional Committee for Africa of WHO: Patient safety in African health services: Issues and solutions: Yaounde, Republic of Cameroon 2008.

9. Tsion Assefa, Mirkuzie Woldie, Shimeles Ololo, Kifle Woldemichael. Patient safety practices and medical errors: Perception of health care providers at Jimma University Specialized Hospital, Southwest Ethiopia 2012; 2: 162-170.

10. AHRQ Hospital Survey on Patient Safety Culture. 2012 User Comparative Database Report: Agency for Healthcare Research and Quality 2012.

11. El-Jardali F, Jaafar M, Dimass H, Jamal D, \& Hamdan R. The current state of patient safety culture in Lebanese hospitals: a study at baseline. International Journal for Quality in Health Care. 2010; 22: 386-395.

12. Evans SM, Berry JG, Smith BJ, Esterman A, Selim PO, Shaughnessy J, et al. Attitudes and barriers to incident reporting: a collaborative hospital study. 2006; 15: 39-43.

13. Kaldjian LC, Jones EW, Wu BJ, Hoffman VLF, Levi BH, Rosenthal GE. Reporting Medical Errors to improving Patient Safety: A Survey of Physicians in Teaching Hospitals. 2008; ;168: 40-46.

14. Lee WC, et al. Hospital Safety Culture in Taiwan: A Nationwide Survey Using Chinese Version Safety Attitude Questionnaire. BMC Health Services Research. 2010; 10: 234.

15. Chen C \& Li H. Measuring patient safety culture in Taiwan using the Hospita Survey on Patient Safety Culture (HSOPSC). BMC Health Service Research. 2010; 10: 152.

16. Institute of Medicine. To err is human: Building a safer health system. Nationa Academy Press, Washing- ton DC; 1999.

17. Jasti $H$, Sheth $H$, Verrico M, Perera PS \& Simak D, et al. Assessing Patient Safety Culture of Internal Medicine House Staff in an Academic Teaching Hospital. 2009; 1: 139-145.

18. Dingley C, Daugherty K, Derieg MK \& Pressing R. Improving Patient Safety through Provider Communication Strategy Enhancements. 2009.

19. Ransom ER, Joshi MS, Nash DB, Ransom SB. The healthcare quality Book Second Edition. 2010.
J Fam Med - Volume 4 Issue 5 - 2017
ISSN : 2380-0658 | www.austinpublishing group.com
Ejajo et al. @ All rights are reserved
Citation: Ejajo T, Arega A and Batebo B. Measuring the Current Patient Safety Culture in Public General Hospitals of Southern Nations Nationalities and Peoples Region (SNNPR), Ethiopia: Perspective of Health Care Workers. J Fam Med. 2017; 4(5): 1124 